\title{
PRODUCTION LOGISTICS SIMULATION SUPPORTED BY PROCESS DESCRIPTION LANGUAGES
}

\author{
Gábor Bohács, Gábor Kovács, Angéla Rinkács \\ Department of Material Handling and Logistics Systems, Hungary \\ Corresponding author: \\ Gábor Kovács \\ Budapest University of Technology and Economics \\ Faculty of Transportation Engineering and Vehicle Engineering \\ Department of Material Handling and Logistics Systems \\ Müegyetem rkp. 3., 1111 Budapest, Hungary \\ phone: $(+36-1)$ 463-5750 \\ e-mail: gabor.kovacs@logisztika.bme.hu
}

Budapest University of Technology and Economics, Faculty of Transportation Engineering and Vehicle Engineering,

Received: 3 September 2015

Accepted: 10 February 2016

\begin{abstract}
The process description languages are used in the business may be useful in the optimization of logistics processes too. The process description languages would be the obvious solution for process control, to handle the main sources of faults and to give a correct list of what to do during the logistics process. Related to this, firstly, the paper presents the main features of the frequent process description languages. The following section describes the currently most used process modelling languages, in the areas of production and construction logistics. In addition, the paper gives some examples of logistics simulation, as another very important field of logistics system modelling. The main edification of the paper, the logistics simulation supported by process description languages. The paper gives a comparison of a Petri net formal representation and a Simul 8 model, through a construction logistics model, as the major contribution of the research.
\end{abstract}

KEYWORDS

process description languages, simulation, logistics, material handling, construction.

\section{Introduction}

The uses of process description languages in the modelling of material flow systems in logistics are scattered. Despite the opportunities and the high number of these languages, it can be found simple flowcharts and only a few applications, which are based on standardized rules. However, during the logistics processes, many problems might arise, which should be addressed already in the planning phase. In our days, the symptomatic treatment is the common practice, but it does not provide predictability. In addition, the possible branching and actions are not defined clearly; moreover there are no clear areas of responsibility. These are the most important failures and drawbacks, in case we don't use formalized process description.

As another strictly important field of the logistics process modelling, the simulation helps to analyze e.g. real production logistics systems. The good simulation model requires precise and lifelike model of the examined logistics system: functions, events, branching, etc. In this field, the process description languages may be useful; and there can be also found some initiations in the literature.

The main goal of our paper is to give an overview of the commonly used process description languages and simulation methods in the field of production and construction processes. We selected these areas as there are in both significant logistic activity. In addition, one sub goal is to give recommendations to improve the current methods, consider the constraints and requirements. As an individual result, we propose a complex approach (process description languages and simulation method) for modelling production logistics systems. 


\section{The main features of the commonly used process description languages}

\section{Petri net (place/transition net)}

The Petri net is a directed bipartite graph, in which the nodes represent transitions (i.e. events that may occur, signified by bars) and places (i.e. conditions, signified by circles). Petri nets offer a graphical notation for stepwise processes that include choice, iteration, and concurrent execution. Petri nets have an exact mathematical definition of their execution semantics, with a well-developed mathematical theory for process analysis.

Dualistic Petri nets (dP-Nets) is a Petri net extension developed by [1] to better represent realworld process; such as computer systems, business processes, traffic flow, etc., to be modelled, studied, and improved.

\section{UML (Unified Modelling Language)}

The UML is a standardized common modelling language, wherewith we can prepare textual and graphical models about systems, organisms. UML can describe participants (their attitude in a system, their connections with other systems, etc.), and it can describe business actions and processes (logical ingredients, their attitude, their tasks, communication in a system or between systems, etc.). UML is developed by the OMG (Object Management Group; OMG website - www.omg.org), and used in software engineering most of all.

ULM is used wide range, but it has got some disadvantage too. It is too big and complicated: contains a lot of diagrams, and some of them are hardly used, some of them are redundant. The semantic is inexact; it is defined partly with UML's own rules, partly textual in English. The austere definition is unfortunately missing from UML; the current standard of UML is continuously developed. In simple programs it takes more time to plan the software in UML than write the program itself.

Anyway, if we'd like to engineer software, which we want to do reproducible by other programmers from another profession field, the UML is an indispensable tool for us. According to our literature review, the application of UML in the formalization of logistics processes is not too frequent.

\section{SysML (Systems Modelling Language)}

The SysML is a general-purpose modelling language for systems engineering applications. It supports the specification, analysis, design, verification and validation of a broad range of systems and systems-of-systems. SysML was originally developed by an open source specification project, and includes an open source license for distribution and use. SysML is defined as an extension of a subset of the Unified Modelling Language (UML) using UML's profile mechanism. With SysML we can use requirement diagrams to efficiently capture functional, performance, and interface requirements, whereas with UML we are subject to the limitations. Likewise, with SysML we can use parametric diagrams to precisely define e.g. performance and quantitative constraints. UML provides no straightforward mechanism to capture this sort of essential performance and quantitative information.

Concerning the rest of the automotive system, enhanced activity diagrams and state machine diagrams can be used to specify the embedded software control logic and information flows for the on-board automotive computers. Other SysML structural and behavioral diagrams can be used to model factories that build the automobiles, as well as the interfaces between the organizations that work in the factories. Based on the beneficial properties, we think that in the future, the logistics system engineering may be one of the most important application areas of SysML.

\section{EPC (Event Driven Process Chain)}

EPC is an ordered graph of events and functions. It provides various connectors that allow alternative and parallel execution of processes. Furthermore, it is specified by the usages of logical operators, such as OR, AND, and XOR. A major strength of the EPC is claimed to be its simplicity and easy-to-understand notation. This makes EPC a widely accepted technique to denote business processes.

EPC diagrams have symbols to show the control flow structure (decisions, functions, events, and other elements) of a business process. EPC diagrams are directed graphs for which no explicit node ordering is provided. There aren't any restrictions on the possible structure of EPCs, but nontrivial structures have ill-defined execution semantics; in this respect they resemble UML. One particular issue is that EPCs require non-local semantics, i.e., the execution behavior of a particular node within an EPC may depend on the state of other parts of the EPC, arbitrarily far away. The structure and toolkit of EPC is very useful to model the logistics processes. There are a few applications from the planning of logistics processes to the consolidation and supporting quality management and logistics information systems. 


\section{IDEF0 (Integrated DEFinition Methods)}

IDEF0 (Idef Website - www.idef.com) is a method designed to model the decisions, actions, and activities of an organization or system. IDEF0 is useful in establishing the scope of an analysis, especially for a functional analysis. As a communication tool, IDEF0 enhances domain expert involvement and consensus decision-making through simplified graphical devices. As an analysis tool, IDEF0 assists the modeler in identifying what functions are performed, what is needed to perform those functions, what the current system does right, and what the current system does wrong.

In IDEF0, the activities can be described by their inputs, outputs, controls, and mechanisms (ICOMs). Additionally, the description of the activities of a system can be easily refined into greater and greater detail until the model is as descriptive as necessary for the decision-making task at hand. The hierarchical nature of IDEF0 facilitates the ability to construct models that have a top-down representation and interpretation, but which are based on a bottom-up analysis process.

In fact, one of the observed problems with IDEF0 models is that they often are so concise that they are understandable only if the reader is a domain expert or has participated in the model development. Another problem with IDEF0 is the tendency of IDEF0 models to be interpreted as representing a sequence of activities. While IDEF0 is not intended to be used for modelling activity sequences (solution: the activities may be placed in a left to right sequence; e.g. one activity outputs a concept that is used as input by another activity, drawing the activity boxes and concept connections is clearer).

\section{BPMN (Business Process Modelling Notation)}

BPMN is the most prevalent process modelling language used in the business sector. BPMN is a graphical modelling method; the main goal is to eliminate the communication troubles among the parties with different backgrounds. It is important to highlight, that BPMN is based on flowchart technique, and it's built from a number of modelling systems, like UML activity diagrams, IDEF0, EPC, etc. It is currently managed by OMG (www.omg.org), the latest version is 2.0 .

The BPMN helps understand internal and external business procedures through a Business Process Diagram. BPMN facilitates communication between users of complex business processes; in addition it is helpful in implementing, monitoring or making a draft of processes. BPMN supports BPEL con- nections (Business Process Execution Language), which is an XML based execution languages. BMPN doesn't include organizational structures and resources, functional breakdowns, data and informational models, business rules and any mechanism for storage. BPMN shows the flow of data and association of data, but it's not a data flow diagram. BPMN is a visual process notation standard; it defines only the look of how the process definition is displayed on the screen.

BMPN is very useful in the logistics, because it has very good notation and visualization structure in the formalization of complex business processes. The visualizations of complex logistics control processes are feasible, and the transparency of the formalized structure is very good.

\section{The role of formalized languages in logistics process description, state of the art}

\section{Material handling processes of production}

The paper [2] presents the general model of static structures (main classes and their relationships) of a production scheduling system supporting discrete and multi-assortment production. In the description of the object-oriented model UML as a graphical system and specifications modelling language notation is used.

In [3] the authors present an approach for a free simulator based on their modelling logic for developing a simulation tool independent description of production systems with SysML. Their aim is to develop an open source simulator, which can simulate all kinds of discrete processes as they can be found for instance in production and logistics systems (TOPCASED, based on the open source simulation framework JAMES II).

In [4] it can be read, that using the IDEF0 method to describe the function of the production line design flow, it can satisfy this complex largescale system analysis and design request. It aims at optimizing the manufacturing of automotive parts to be more scientific and consecutive.

In connection with the production logistics process description, the most commonly mentioned language is the BPMN, due to the above mentioned advantages. On the other hand, the simple BPMN shouldn't be always enough. Paper [5] describes, that the need for modelling the physical object flow cannot efficiently be addressed with BPMN in which even in some processes the continuity of object flows act as either instantiation, or resumption of the 
process. Therefore, UML diagrams are used to address the problem due to capability of modelling the flow of objects and object semantics. In [6] can be read how BPM can be applied in the manufacturing domain. In this paper, there are proposed BPMN extensions to support process modelling in the manufacturing domain, especially the modelling of production processes, such as: manufacturing task, parts container, material select gateway, etc. BPMN supports lower level languages, such as BPEL and XML. Paper [7] proposes a method based on graph grammars to convert from BPMN to BPEL codes. In [8] it can be shown how functional logic programming techniques can be used to construct a bidirectional transformation between structured process models of the business process modelling notation (BPMN) and executable models of the business process execution language (BPEL).

It seems that BPMN, UML, SysML and IDEF0 have some successful applications in the field of production logistics. In addition, there is a much simpler way to describe one process: the Petri net. Paper [9] presents a new redesigned solution for container terminal production processing system. The integrity and credibility of the new system was proved using Petri net analysis. The new development solution is to improve some disadvantages existed in the old system and to rebuild logistics processes with low cost, high quality, more flexible, faster and smart responsiveness, in the whole terminal production system. In [10], the authors analyses the features and effects of the production logistics system, eventually comes up with some improvement strategies and optimizations addressing the identified bottleneck problems, using Petri net + Flexsim simulation software.

\section{Construction processes}

UML is highly expressive and rich in notations and can support successfully the concept modelling of the construction information system. Paper [11] also mentions an application of UML. The modelling of the OPDT (on-site project document) system with UML for construction processes is recommended because the various aspects of the construction information system can be precisely visualized, specified and documented.

The most common used standardized process description language in the construction process is the IDEF0 diagram. In paper [12] it is modelled the overall construction process systematically creating a generic state-of-the-art IDEF0 model that covers the design and construction of a building project from the conception of the project in a client's mind to its completion for handover and use. This study gives detailed lists of activities and flows of construction processes. This is a good example to create construction process IDEF0 diagram. Research [13] presents the role of information technology in construction processes. A model of the information and material activities which together constitute the construction process is presented, using the IDEF0 activity modelling methodology. Study [14] proposes the concept of IDEF0 modelling methods and provides a prototype used for designing construction knowledge management systems. Over and above, in paper [15] it be using the method of IDEF0 to portray the contents of a management information system for schedule delay analysis. Sometimes, the IDEF0 method is in association with other process description methods. Research [11] uses IDEF0 and UML to develop the electronic document management of construction processes. IDEF0 is responsible for overall process description: activities and information flow between the activities. It can be found in UML the detailed description of procedures, rules and messaging.

Paper [16] demonstrates the modelling of construction supply chains using the Supply Chain Operations Reference (SCOR) framework. The SCOR modelling framework provides a structured and systematic way to model and disaggregate a supply chain from conceptual representation to process element specification. The SCOR framework is commonly used by corporations for strategic planning of their supply chains. The SCOR models are represented in BPMN standard.

Paper [17] presents a Petri net model of a concrete placing operation. Moreover, it establishes that Petri nets may be useful in the high-fidelity modelling of automated construction operations.

\section{The role of simulation in logistics processes}

In [18] it is described application fields of simulations in logistics and supply chain. They found that a thorough classification of the topics covered in the supply chain literature has not been found. Generally speaking three main areas are covered [19]:

- network design,

- analysis and policy formulation,

- supply chain planning and scheduling.

More specifically simulation modelling may serve different purposes. Next list from [18] collects various strategic and operational issues form the field of logistics:

- Supply Chain Structure (SCS),

- Process Redesign (BPR),

- Supplier Selection (SS), 
- Facilities/ Capacity Planning (FCP),

- Supply Chain Integration (SCI),

- Information Sharing (ISH),

- Bullwhip Effect (BE),

- Reverse Logistics (RL),

- Replenishment Control Policies (RCP),

- Supply Chain Optimization (SCO),

- Cost Reduction (CR),

- System Performance (SP),

- Inventory Planning/Management (IPM),

- Planning \& Forecasting Demand (PFD),

- Production Planning \& Scheduling (PP-SCH),

- Distribution \& Transportation Planning (DTP),

- Dispatching Rules (DR).

Above listing is not in alphabetical order, the top ones address strategic, and the low ones operational issues. Simulations can be implemented using two different approaches: Discrete event simulation (DES) and system dynamics (SD). Both principles are accepted and it is widely agreed that SD simulations are preferred for strategic and DES for operational issues. Certainly the goal of a simulation and the so the necessary KPI's determine the applicable simulation model as well.

Gola and Świć presented in their paper [21] simulation model of an FMS system. In their approach the model's structure follows the functional grouping of the production system's physical components. A similar approach is presented in [22]. Kłos and Trebuna in their paper [23] presented a model which follows in construction the material flow.

Rostkowska in her paper [24] points out that simulation software which can model only logic diagrams may have the drawback that systems could be modelled unregarded the physical restrictions. This is a general flaw of simulators in the virtual world, which must be handled by separate computing algorithms. Logistics simulations in most cases simply oversee such problems.

From the above we concluded that the structure building of a simulation model follows personal consideration of the expert regarding the specifics of the modelled system. Selection of the simulation environment is also determined by the expert's software knowledge and the problem.

There are many ready-made software for simulation discrete processes (eg. Flexsim, Enterprise Dynamics, Arena, Matlab-SimEvents toolbox) which are directly dedicated for simulation logistic and production processes. Our approach differs from the general solutions in the construction order of the model. As process description languages may effectively help by the problem's formulation we concluded that the simulation modelling process itself shouldn't be independent from the formal language description, possible synergies must be exploited. First simulation model components are defined, which can be matched directly to the components of the modelling language. The final model is then constructed from exactly these components, matching the existing formal language representation. That way a clear, wellstructured representation can be achieved. As there are many available simulation software environments from this point the following restriction is made: we will concentrate for an implementation in Simul8 environment (http://www.simul8.com). Simul8 simulations has several structural elements, but in order to remain general we used only two elements:

- Work centers,

- Storage areas.

Work centers are active elements capable of managing input and output relations. Storage areas are passive elements. Figure 1 shows related Simul8 pictograms on the left side. These two elements are analogous to the two structural elements of the Petri nets, Places and Transitions (shown on the right side of Fig. 1).

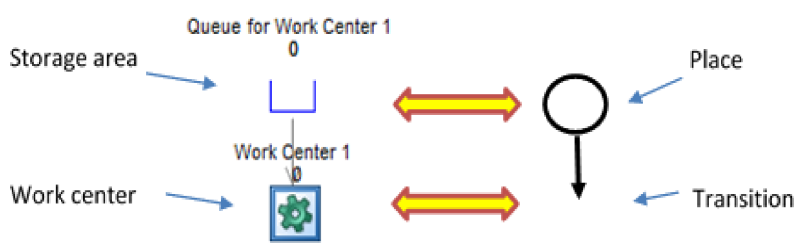

Fig. 1. Analogy of Simul8 and Petri net components.

It should be remarked that these two basic elements can be found in most simulation languages that means this modelling way is almost platform independent.

Researchers already recognized and applied possible automatic conversions between formal representations and simulation models. Paper [14] describes a software tool that can generate an integrated model of a functional product from its design details and analyze it through simulation to provide availability performance information. The tool is capable of converting a description of a functional product in terms of its design details into a model, analyzing the generated model through simulation and providing various predictions, such as those related to functional availability, on its performance.

In our approach we found also advantages to apply a model described by Petri net, because its structure and the basic elements of the Simuls model as shown in the example of next chapter 5 is very suitable for the direct implementation in simulation environment. 


\section{Logistics simulation supported by process description language}

Relation of a formal representation (e.g. Petri net) and a simulation software (Simul8) for a selected logistics area is presented as follows. The example is a construction site's logistics model (see Fig. 2).

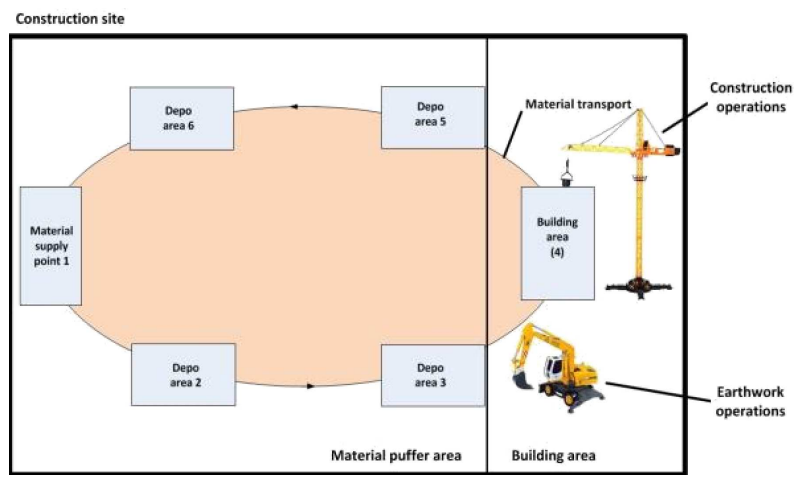

Fig. 2. Construction logistics model example.

All materials arrive at the construction site on the "Material supply point 1". These will be first transported to the corresponding Depo area. Building processes are carried out at the "Building area (4)". For the sake of simplicity each building operation is composed of a first earthwork and a consecutive construction operation. Construction operations may only start if the necessary materials are already transported to the building area. Table 1. shows some example processes for the model presented in Fig. 2. Figure 3 shows the Petri net and the Simul 8 model.

Table 1

Listing of process elements.

\begin{tabular}{c|l|c}
\hline Process ID & \multicolumn{1}{|c}{ Description } & $\begin{array}{c}\text { Precondition } \\
\text { process }\end{array}$ \\
\hline 1 & Earthwork & - \\
\hline 2 & $\begin{array}{l}\text { Material transport of } 101 \text { from } \\
1 \text { to } 2\end{array}$ & - \\
\hline 3 & $\begin{array}{l}\text { Material transport of } 102 \text { from } \\
1 \text { to } 3\end{array}$ & - \\
\hline 4 & $\begin{array}{l}\text { Material transport of } 103 \text { from } \\
1 \text { to } 5\end{array}$ & - \\
\hline 5 & $\begin{array}{l}\text { Material transport of } 104 \text { from } \\
1 \text { to } 6\end{array}$ & - \\
\hline 6 & $\begin{array}{l}\text { Material transport of } 101 \text { from } \\
2 \text { to } 4\end{array}$ & 1,2 \\
\hline 7 & $\begin{array}{l}\text { Material transport of } 102 \text { from } \\
3 \text { to } 4\end{array}$ & 6,7 \\
\hline 8 & Construction 1 & 8 \\
\hline 9 & Earthwork 2 & 5,9 \\
\hline 10 & $\begin{array}{l}\text { Material transport of } 103 \text { from } \\
5 \text { to } 4\end{array}$ & $\begin{array}{l}\text { Material transport of } 104 \text { from } \\
6 \text { to } 4\end{array}$ \\
\hline 11 & Construction 2 & 11 \\
\hline & & \\
\hline 12 & & 10,9 \\
\hline
\end{tabular}

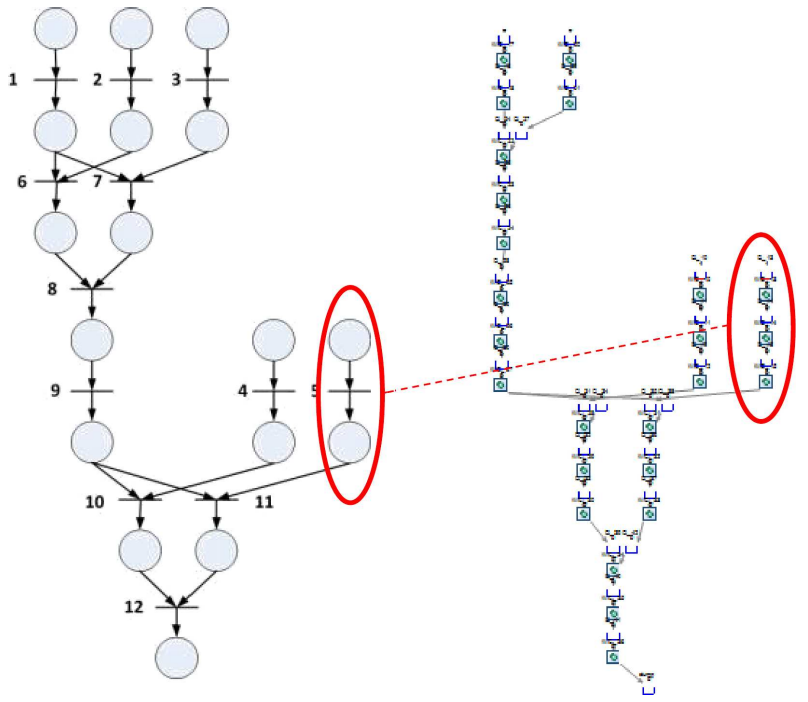

Fig. 3. Comparison of a Petri net formal representation (left) and a Simul8 model (right).

As seen it includes the building operations and the related movements of materials to the Depo and further to the building area.

An important issue for the execution of the processes are preconditions. Main use of a formal representation is to present these dependencies. Figure 3 compares representation of the example process using a Petri-net and a Simul8 simulation model.

By seeing Fig. 3 similar structure of the two representations is obvious. In the Petri net each process (a selected one is encircled by red) is modelled by two places, which symbolize the system's states before and after the process. In Simul8 these elements are supplemented by an additional Work center afterwards, which serve only as a hub for signal forwarding. The first Storage area and Work center pair has only the functionality to collect the incoming signals and unite them if all the preconditions are met.

\section{Conclusions}

This paper analyzed from various aspects of the application of process description languages in two areas of logistics. Additionally, analogies of a selected process description language and a simulation software were also described. It was concluded that these analogies can be preferably exploited during the construction of the simulation model. As the conversion this way between the formal representation and the simulation model is very straightforward, it can be a good basis for an automatic conversion.

Next step of the research will be the discovery of this area as it would enable structural adaptive simu- 
lations, which are almost indispensable from the view of modern adaptive logistic systems.

This paper is a part of our research project (KTIA-AIK-12-1-2013-0009) financed by the National Development Agency of Hungary, total financial support is HUF 419904851 which aims to improve logistics processes in the building industry.

\section{References}

[1] Dawis E.P., Architecture of an SS7 protocol stack on a broadband switch platform using dualistic petri nets, Communications, Computers and signal Processing, PACRIM 2001, IEEE Pacific Rim Conference, 1, 323-326, 2001,

DOI: 10.1109/PACRIM.2001.953588.

[2] Kalinowski K., Grabowik C., Paprocka I., Kempa W.M., The model of discrete production scheduling system in UML notation-classes diagrams, Advanced Materials Research, 837, 416-421, 2014, DOI: 10.4028/www.scientific.net/AMR.837.416.

[3] Schonherr O., Moss J.H., Rehm M., Rose O., A free simulator for modelling production systems with SysML, Simulation Conference (WSC), Proceedings of the 2012 Winter, pp. 1-12, 2012, DOI: 10.1109/WSC.2012.6465090.

[4] Chai S.F., Luo S.J., Bai L.N., Chai G.W., Virtual Production Line Design Based on the IDEF0 Method, Applied Mechanics and Materials, 274, 3336,2013 ,

DOI: 10.4028/www.scientific.net/AMM.274.33.

[5] Khabbazi M.R., Hasan M.K., Sulaiman R., Shapi'i A., Taei-Zadeh A., Business Process Modelling in Production Logistics: Complementary Use of $B P M N$ and $U M L$, Middle-East Journal of Scientific Research, 15, 4, 516-529, 2013,

DOI: 10.5829/idosi.mejsr.2013.15.4.2280.

[6] Zor S., Leymann F., Schumm D., A proposal of $B P M N$ extensions for the manufacturing domain, Proceedings of 44th CIRP international conference on manufacturing systems, 2011.

[7] Shi Z., Zeng X., Huang S., Li H., Hu B., Lei X., Wang Y., Transformation between BPMN and BPEL based on graph grammar, Computing, Communication and Networking Technologies (ICCCNT), International Conference, pp. 1-6, 2014, DOI: 10.1109/ICCCNT.2014.6963105.

[8] Mazanek S., Hanus M., Constructing a bidirectional transformation between BPMN and BPEL with a functional logic programming language, Journal of Visual Languages \& Computing, 22, 1, 66-89, 2011, DOI: $10.1016 /$ j.jvlc.2010.11.005.
[9] Zhong W.Z., Fu X. Q., Wang Y.P., Petri Net Modelling: Container Terminal Production Operation Processing System Analysis, Applied Mechanics and Materials, 409, 1320-1324, 2013,

DOI: 10.4028/www.scientific.net/AMM.409-410.1320.

[10] Qian Z., Sun H., A Simulation Study on Production Logistics Balance Based on Petri Net+ Flexsim, International Conference on Education Technology and Information System (ICETIS 2013).

[11] Rezgui Y., Hopfe C.J., Vorakulpipat C., Generations of knowledge management in the architecture, engineering and construction industry: An evolutionary perspective, Advanced Engineering Informatics, 24, 2, 219-228, 2010, DOI: $0.1016 /$ j.aei.2009.12.001.

[12] Cempela W.A., Mikulika J., Intelligent building reengineering: adjusting life and work environment to occupant's optimal routine processes, Intelligent Buildings International, 5, 1, 51-64, 2013, DOI: 10.1080/17508975.2012.760440.

[13] Björk B.C., Samuelson O., Adoption processes for EDM, EDI and BIM technologies in the construction industry, Journal of Civil Engineering and Management, 19, 1, 172-187, 2013, DOI: 10.3846/13923730.2013.801888

[14] Tserng H.P., Yin S.Y.L., Lee M.H., The use of knowledge map model in construction industry, Journal of Civil Engineering and Management, 16, 3, 332-344, 2010, DOI: 10.3846/jcem.2010.38.

[15] Yang J.B., Kao C.K., Critical path effect based delay analysis method for construction projects, International Journal of Project Management, 30, 3, 385397, 2012, DOI: 10.1016/j.ijproman.2011.06.003.

[16] Cheng C.P., Law K.H., Bjornsson H., Jones A., Sriram R.D., Modelling and monitoring of construction supply chains, Advanced Engineering Informatics, 24, 435-455, 2010, DOI: 10.1016/j.aei.2010.06.009.

[17] Cheng F.F., Wang Y.W., Ling X.Z., Bai Y., A Petri net simulation model for virtual construction of earthmoving operations, Automation in Construction, 20, 2, 181-188, 2011, DOI: $10.1016 /$ j.autcon.2010.09.015.

[18] Antuela A., Tako, Stewart R., The application of discrete event simulation and system dynamics in the logistics and supply chain context, Decision Support Systems, 52, 802-815, 2012.

[19] Shah N., Process industry supply chains: advances and challenges, Computers and Chemical Engineering, 29, 1225-1235, 2005.

[20] Löfstrand M., Kyösti P., Reed S., Backe B., Evaluating availability of functional products through sim- 
ulation, Simulation Modelling Practice and Theory, 47, 196-209, 2014.

[21] Gola A., Świć A., Design of storage subsystem of flexible manufacturing system using the computer simulation method, Actual Problems of Economics, 142, 4, 312-318, 2013.

[22] Osak-Sidoruk M., Gola A., Świć A., A method for modelling the flow of objects to be machined in FMS using Enterprise Dynamics, Applied Computer Science, 10, 3, 46-56, 2014.
[23] Kłos S., Trebuna P., Using computer simulation method to improve throughput of productions systems by buffers and workers allocation, Management and Production Engineering Review, 6, 4, 60-69, 2015, DOI: 10.1515/mper-2015-0037.

[24] Rostkowska M., Simulation of production lines in the education of engineers: how to choose the right software, Management and Production Engineering Review, 5, 4, 53-65, 2014, DOI: $10.2478 /$ mper-2014-0036. 